\title{
DESENVOLVIMENTO DE UM CALÇADO PARA MULHERES COM JOANETE: UMA ABORDAGEM CENTRADA NO USUÁRIO
}

\section{DEVELOPMENT OF WOMEN'S FOOTWEAR FOR BUNION: A USER CENTERED APPROACH}

\author{
Letícia Takayama ${ }^{1}$, Grad. \\ Giselle Schmidt Alves Diaz Merino², Dr. ${ }^{\mathrm{a}}$ \\ Eugenio Andres Diaz Merino ${ }^{3}$, Dr. \\ (1) Universidade Federal de Santa Catarina \\ e-mail: takayamaleticia@gmai.com \\ (2) Universidade Federal de Santa Catarina \\ e-mail: gisellemerino@gmail.com \\ (3) Universidade Federal de Santa Catarina \\ e-mail: eugenio.merino@ufsc.br
}

\section{Design Centrado no Usuário, Calçado, Joanete}

Um dos fatores de surgimento do joanete é o uso de calçados inadequados que deformam os pés. A escolha certa deste produto melhora a saúde, bem-estar e conforto de mulheres que possuem este problema. Este artigo tem como objetivo definir os requisitos do usuário e produto para a elaboração de um modelo conceitual de calçado para mulheres com joanetes.

\section{User Centered Design, Shoe, Bunion}

One of the factors that causes bunions is the use of inappropriate shoes that can deform the feet. Thus, the right shoes can improve health, well-being and comfort for women who have this problem. This article aims to define the requirements about the user and product to develop a conceptual model of footwear for women with bunions.

\section{Introdução}

O calçado, em seu princípio, tem papel de proteger os pés do ambiente externo e possibilitar a locomoção com redução de dores. Entretanto, o uso prologado de calçados inadequados, que não foram projetados para a proteção, pode resultar na alteração morfológica dos pés, reduzir ou prejudicar a estabilidade postural do corpo, causar desiquilíbrio muscular e ajudar no 
desenvolvimento de pés mais sensíveis [GOONETILLEKE, 2012].

Mulheres que possuem problemas nos pés, como o joanete, têm maior dificuldade em encontrar calçados apropriados. Como um dos fatores de surgimento e agravamento do joanete é o uso de calçados inadequados, a escolha certa deste produto pode melhorar a saúde, bem-estar e conforto das usuárias. Neste sentido, o presente artigo tem como objetivo definir requisitos e elaborar um modelo conceitual de calçado para mulheres com joanete pela abordagem centrada no usuário e critérios de funcionalidade e estética.

\section{Problemas com o joanete}

O joanete (Figura 1) é a palavra popular para a deformação no hálux, primeiro dedo do pé. Ele é causado pelo desvio lateral da falange proximal do hálux sobre a cabeça do primeiro metatársico. Quando este desvio ocorre, outros problemas se instalam, como o deslocamento lateral dos tendões flexores, extensores e ossículos sob a cabeça do primeiro metatársico, alargamento da porção interna da cabeça do metatársico e saliência óssea (exostose) [NERY, 2008].

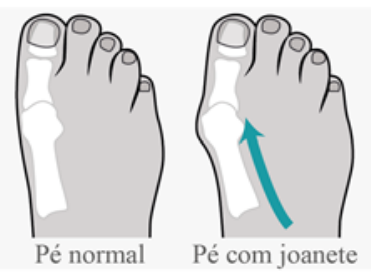

Figura 1: Pé normal e o pé com joanete Fonte: Os autores

O joanete pode ser causado pela ação direta de calçados que forçam a estrutura do antepé a permanecer dentro de uma câmara triangular. Ele geralmente atinge mulheres adultas entre 40 e 50 anos e além da deformação na região metatarsofalângica, outros problemas comuns relacionados ao joanete são: calos, dores no metatarso e feridas no segundo dedo. $\mathrm{O}$ tratamento é feito por cirurgia e uso de calçados especiais com câmara anterior ampla e palmilhas de acomodação para a prevenção do agravamento da doença [NERY, 2008].

\section{Ergonomia no design de calçados}

A ergonomia centrada no usuário tem como diferencial a abordagem a partir do pronto de vista do usuário, não sendo elaborada a partir da associação do usuário/produto. No design de calçados, a ergonomia atua na adequação do produto às condições físicas dos pés do usuário em seu contexto de uso. Até hoje, a grande maioria dos calçados é produzida de modo industrial, por modelos padronizados de moldes de pés e pernas. O tamanho dos calçados baseia-se em configurações dimensionais, chamadas de numerações, estabelecidas ergonomicamente por meio de dados estatísticos antropomórficos de várias faixas da população [MORAES; MONT'ALVÃO, 2010; GOMES FILHO, 2003].

Mesmo com estudos de melhoria antropométrica dos calçados, ainda há problemas relacionados à ergonomia e conforto. Alguns destes problemas são: inadequação entre o calçado e o usuário, inadequação dos materiais usados, incompatibilidade do calçado com a função exercida pelo usuário, escolha de tamanho errado pela falta de numerações quebradas (ex: 37,5) e pouca disponibilidade de modelos para pessoas com pés maiores que a numeração 42 [GOMES FILHO, 2003].

\section{Conceitos de conforto e estética}

A definição de conforto está relacionada ao estado de alívio, agrado e satisfação. O conforto é subjetivo e possui inúmeras variáveis que mudam de pessoa para pessoa. Em relação aos calçados, os fatores que influenciam no conforto físico são: tamanho, odores, textura, sensação do calçado nos pés, sons que os calçados emitem, temperatura e umidade dentro do calçado. [GOONETILLEKE, 2012].

Já o conforto psicológico está relacionado ao bemestar, satisfação e aparência dos indivíduos perante outros membros da sociedade. Neste sentido, a moda, o estilo, a personalidade, a sexualidade, a classe e o gênero estão relacionadas ao conforto psicológico, que por sua vez, influenciam significantemente na decisão de compra dos 
$16^{\circ}$ Ergodesign - Congresso Internacional de Ergonomia e Usabilidade de Interfaces Humano Tecnológica: Produto, Informações Ambientes Construídos e Transporte

$16^{\circ}$ USIHC - Congresso Internacional de Ergonomia e Usabilidade de Interfaces Humano Computador

indivíduos. A estética também entra no conceito de conforto psicológico. No consumo do objeto de moda, os conceitos de beleza deixam de ser atribuídos ao objeto para fazerem parte da estética do próprio indivíduo. Deste modo, a estética do belo é inerente a cada indivíduo e define seu comportamento de consumo pelo conforto estético que se almeja [SOUZA; HELD, 2011].

Pelo estudo destes conceitos, foi possível determinar elementos essenciais que serão base para a etapa de geração de requisitos de projeto, como: tamanho adequado, sistema de prevenção de odores, textura agradável, regulação de temperatura e umidade interna, redução de ruídos e estética agradável.

\section{Metodologia}

Esta pesquisa caracteriza-se como um estudo exploratório dividido em quatro etapas sobre calçados para mulheres com joanetes. A primeira etapa possui cunho teórico pesquisado em publicações nas línguas portuguesa e inglesa em livros, pesquisas do governo, relatórios técnicos e bases de dados. Para a busca de artigos, utilizou-se a combinação das palavras: "hálux valgo/hallux valgo", "joanete/bunion", "calçado/shoe", "ergonomia/ergonomics" e "saúde/health". Os dados usados como referência fazem relação ao joanete e as repercussões sobre o conforto, saúde e estética de calçados para esta patologia.

A segunda etapa é uma análise sincrônica dos modelos de calçados especiais para pés com joanete no mercado brasileiro entre os meses de outubro e novembro do ano de 2016. Para esta análise foram pesquisados sites que comercializam marcas nacionais de calçados a fim de levantar dados sobre as potenciais melhorias no desenvolvimento de sapatos para joanetes.

As pesquisas com os usuários foram realizadas na terceira etapa. Os questionários foram aplicados online e obtiveram 42 respostas de mulheres entre 20 e 69 anos. Por sua vez, as entrevistas foram feitas presencialmente com 8 mulheres entre 23 a 84 anos. Vale ressaltar que a coleta de dados foi realizada com cuidados éticos de pesquisa pela assinatura do Termo de Consentimento Livre e Esclarecido - TCLE pelos usuários participantes.

$\mathrm{Na}$ quarta etapa foram definidos requisitos de projeto relacionados ao produto e ao usuário. Estes itens gerados serviram de base para a criação de um modelo de calçado conceitual para mulheres com joanetes.

\section{$6 \quad$ Etapa 2}

Na segunda etapa da pesquisa foi feita a análise sincrônica dos modelos de calçados femininos para joanetes do ano de 2016. As empresas brasileiras selecionadas para esta análise foram: Doctor Pé, Doctor Shoes, Campesí, Usaflex, Piccadilly e Comfortflex. Diferentes modelos de calçados de cada empresa foram selecionados para aumentar a variedade de estilos analisados (Figura 2).

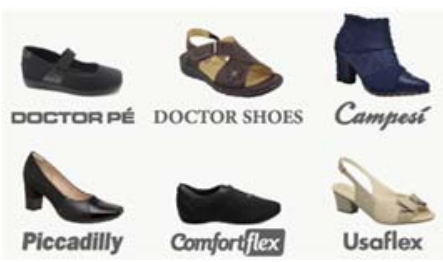

Figura 2: Modelos de calçados para joanetes analisados Fonte: Os autores

O Quadro 1 mostra a síntese dos itens observados em cada modelo de calçado das empresas analisadas.

\begin{tabular}{|c|l|}
\hline \multicolumn{2}{|c|}{ ANÁLISE DOS CALÇADOS PARA JOANETES } \\
\hline Modelos & Bota, sandália, sapatilha, scarpin e tênis \\
\hline Preço & Entre R\$164,99 e R\$199,90 \\
\hline Cabedal & $\begin{array}{l}\text { Couro, o neoprene e tipos de tecido elásticos na } \\
\text { região do joanete }\end{array}$ \\
\hline Solado & Poliuretano e outros tipos de borracha \\
\hline Palmilha & $\begin{array}{l}\text { Poliuretano, com variações em látex, E.V.A. ou } \\
\text { manta de biofibra }\end{array}$ \\
\hline Forro & Couro, tecido espumado ou cacharrel \\
\hline Salto & Entre $1,5 \mathrm{~cm}$ a $7,4 \mathrm{~cm}$ \\
\hline Peso & Entre $524 \mathrm{~g}$ a $600 \mathrm{~g}$ \\
\hline Outras & $\begin{array}{l}\text { Forma mais ampla, cabedal elástico e maior } \\
\text { estabilidade }\end{array}$ \\
\hline características
\end{tabular}

Quadro 1: Análise dos calçados para joanetes Fonte: Os autores

Por esta análise, pôde-se observar os tipos de calçados encontrados possuem uma grande variedade de modelos. Os preços dos produtos 
tiveram pouca variação entre os calçados, sendo que o mais caro era vendido por $\mathrm{R} \$ 199,90$ e o mais barato $\mathrm{R} \$ 164,99$. Os materiais mais usados no cabedal foram o couro, o neoprene e tipos de tecido elásticos na região do joanete. Já os solados foram fabricados com poliuretano e outros tipos de borracha não especificados pelas empresas. As palmilhas dos calçados analisados também eram feitas de poliuretano, com outras variações em látex, E.V.A. ou manta de biofibra. Já os forros pesquisados eram feitos em couro, tecido espumado ou cacharrel. Embora o uso de calçados com salto alto não seja adequado para mulheres com joanetes, tiveram variações de altura que entre $7,4 \mathrm{~cm}$ à $1,5 \mathrm{~cm}$. Por outro lado, o peso possuiu pouca oscilação entre os modelos e variou de $524 \mathrm{~g}$ a $600 \mathrm{~g}$. Outras características mais específicas de cada modelo de calçado foram selecionadas como: forma mais ampla, cabedal elástico e maior estabilidade.

\section{$7 \quad$ Etapa 3}

$\mathrm{Na}$ terceira etapa da pesquisa, foram coletados dados com mulheres que possuem joanetes em forma de questionário e entrevista.

O questionário foi aplicado em uma plataforma online, entre os dias entre os dias 17 e 21 de outubro de 2016 e obteve 42 respostas de mulheres com média de 20 a 49 anos. Em relação as entrevistas, estas ocorreram presencialmente com 8 mulheres de 23 a 84 anos, entre os dias 18 de outubro e 4 de novembro de 2016. O levantamento de dados ocorreu com cuidados éticos de pesquisa pela assinatura do Termo de Consentimento Livre e Esclarecido - TCLE pelos usuários participantes.

\subsection{Questionário}

Foi aplicado um questionário online entre os dias 17 e 21 de outubro de 2016. Este questionário obteve 42 respostas de mulheres que possuem joanetes. A média de idade variou de 20 a 49 anos, sendo que $36 \%$ das pessoas tinham entre 20 e 29 anos, $31 \%$ entre 40 e 49 anos, $12 \%$ entre 30 e 39 anos, $10 \%$ entre 50 e 59 anos e $10 \%$ entre 60 e 69 anos. Pelo questionário, pôde-se observar que a média aritmética da idade de desenvolvimento do joanete é de cerca de 15 anos, sendo que a metade das mulheres que participaram da pesquisa desenvolveram o joanete desde a infância ou adolescência. Quanto ao tamanho do joanete, 52\% das mulheres classificaram esta deformação como de tamanho pequeno, $36 \%$ médio e $12 \%$ grande.

Cerca de $69 \%$ das mulheres que responderam o questionário possuíam dificuldades em encontrar calçados por causa do joanete. Uma das reclamações mais comuns foi a largura do sapato, que muitas vezes não é adequada aos pés e apertam na parte do joanete. As costuras laterais, o bico fino e as tiras laterais na área do joanete também foram alvos de reclamação entre as entrevistadas. Muitas mulheres relataram comprar calçados com numerações maiores que possuam a lateral mais larga.

Segundo o questionário, a maioria das mulheres se considerava vaidosa ( $86 \%$ ) e cerca de $76 \%$ delas já usou um calçado desconfortável levando em consideração apenas a sua estética. Os modelos de calçado mais usados foram o tênis (81\%), sapatilha $(57 \%)$, bota $(48 \%)$, chinelo (43\%), sandália (38\%), mocassim (14\%), oxford (14\%) e sapato de salto (14\%). Por fim, muitas mulheres que responderam o questionário relataram que nunca usaram calçados especiais para joanetes $(88 \%)$.

\subsection{Entrevista}

Foram elaboradas entrevistas semiestruturadas com 8 mulheres de 23 a 84 anos entre os dias 18 de outubro e 4 de novembro de 2016. As entrevistas foram realizadas pessoalmente e nela foram feitas perguntas sobre o tempo de desenvolvimento do joanete, sua natureza, tipo de calçado que costuma usar e os problemas com o conforto nos pés. Entre as entrevistadas, quatro delas possuem joanete genética, três possuem joanete pelo uso prolongado de calçados inadequados e uma delas desenvolveu o joanete devido a uma doença degenerativa, como o diabetes. Muitas das entrevistadas relataram dores na região do joanete, sendo que algumas delas também possuíam inchaço nos pés.

Os modelos de calçados mais usados pelas entrevistadas foram a sapatilha, o chinelo, o tênis e 
$16^{\circ}$ USIHC - Congresso Internacional de Ergonomia e Usabilidade de Interfaces Humano Computador

a bota e as marcas de calçado mais usadas foram a Usaflex, Piccadilly e Comfortflex. De acordo com uma das entrevistadas, o verão é a época do ano mais difícil de encontrar calçados adequados, pois muitos modelos possuem tiras nas laterais, que machucam a região do joanete, e são mais abertos, o que causa o constrangimento por causa da estética dos pés. Outra entrevistada relatou que usa um modelo de calçado especial para diabetes, que possui maior conforto e segurança para evitar lesões nos pés. Entretanto, esta entrevistada relatou que acha este modelo "feio" e muitas vezes opta por usar outro tipo de calçado pela estética.

\section{Resultados}

Pela pesquisa no mercado brasileiro, foi constatado que os modelos de calçados especiais para pés com joanetes possuem características semelhantes, como: uso de materiais elásticos na lateral dos pés e forma mais ampla.

O questionário apontou que a maioria das mulheres se considerava vaidosa ( $86 \%$ ) e preferia usar um calçado pela sua estética independente do conforto (76\%). Este dado relacionado ao joanete é alarmante, pois o uso de calçados inadequados pode agravar o estado da deformação causando dor e desconforto.

Pelas entrevistas notou-se que muitas mulheres possuíam pré-disposição genética para o desenvolvimento de joanetes. Deste modo, o tratamento e prevenção de deformações pelo uso de calçados inadequados pode influenciar gerações de consumidores. Tanto pelo questionário quanto pela entrevista, os modelos de calçados mais usados foram o tênis, a sapatilha e a bota, que servirão de base para a escolha do sapato a ser desenvolvido pelo projeto deste artigo. Além disso, o calçado a ser desenvolvido, segundo a coleta, também não deverá possuir alguns quesitos como costuras laterais, bico fino, abertura nos dedos ou tiras na parte do joanete.

\section{Etapa 4}

$\mathrm{Na}$ quarta etapa da pesquisa, foram consideradas as informações obtidas pelos estudos teóricos somados aos questionários e entrevistas. Pelo levantamento destas informações, foram identificadas as necessidades de projeto posteriormente traduzidas na forma de requisitos. O Quadro 2 representa os requisitos dos usuários agrupados em saúde, conforto e segurança.

\begin{tabular}{|l|l}
\hline Saúde & \multicolumn{1}{c}{ REQUISITOS DO USUÁRIO } \\
& - Ter a base correspondente à largura do pé e calcanhar; \\
- Reduzir ou evitar o crescimento do joanete; \\
- Não possuir áreas que possam causar ulcerações nos \\
pés; \\
- Adequar a distribuição de peso do corpo sobre a \\
palmilha; \\
- Possuir bom calce sem pressões excessivas; \\
- Ser adaptável a diferentes larguras de pés e tamanhos \\
de joanetes; \\
- Promover estabilidade durante a marcha; \\
- Permitir ajuste fácil e seguro; \\
- Possuir estética agradável adequada às tendências de \\
moda; \\
- Camuflar o joanete para evitar o constrangimento \\
causado por esta deformação; \\
- Ser um modelo de tênis, sapatilha ou bota, para ter \\
maior aceitação dos usuários. \\
Quadro 2: Requisitos do Usuário \\
$\quad$ Fonte: Os autores
\end{tabular}

A partir do resultado da coleta e dos dados descritos anteriormente, foi possível definir requisitos do produto, traduzidos no Quadro 3.

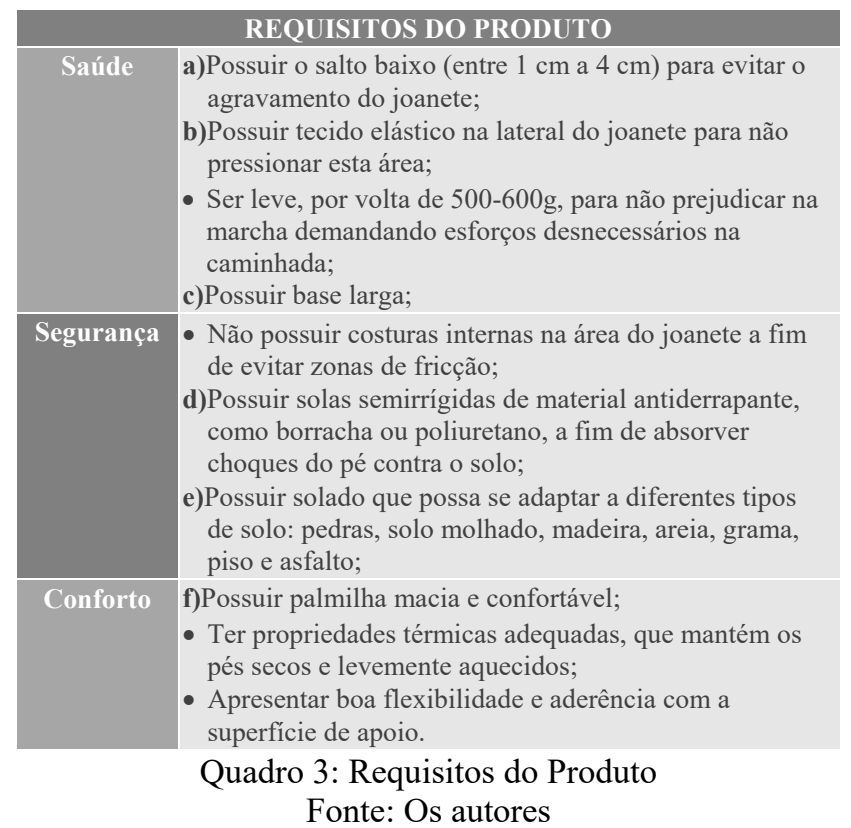

Fonte: Os autores 
$16^{\circ}$ Ergodesign - Congresso Internacional de Ergonomia e Usabilidade de Interfaces Humano Tecnológica: Produto, Informações Ambientes Construídos e Transporte

$16^{\circ}$ USIHC - Congresso Internacional de Ergonomia e Usabilidade de Interfaces Humano Computador

Com base nos requisitos listados, foi desenvolvido um modelo de sapatilha conceitual para mulheres com joanete (Figura 4 e Figura 5). Os itens destacados na figura representam os requisitos de produto apresentados no quadro anterior.

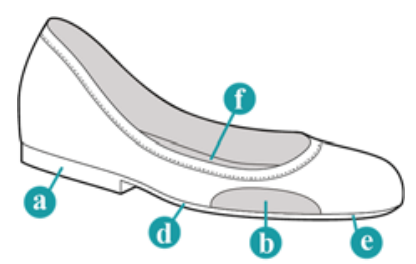

Figura 4: Modelo conceitual - vista perspectiva Fonte: Os autores

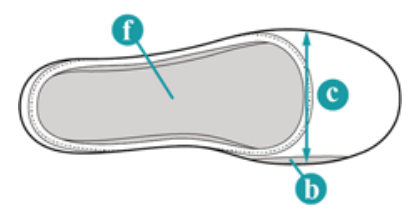

Figura 5: Modelo conceitual - vista superior Fonte: Os autores

\section{Conclusão}

O desenvolvimento do calçado ideal deve levar em conta tanto os aspectos ergonômicos do produto, quanto suas características estéticas e funcionais para satisfazer o conforto físico e psicológico do usuário. Para mulheres que possuem problemas nos pés, como o joanete, a escolha do calçado adequado é essencial para evitar dores e lesões.

A análise dos calçados para joanetes apontou a necessidade de projetos voltados para esta área. Do mesmo modo, também foi possível analisar os detalhamentos dos componentes destes modelos nos quesitos modelo, material, preço, salto e peso. Por outro lado, os questionários e entrevistas, levantaram dados importantes sobre o público alvo e demonstraram que muitas vezes, as mulheres preferem usar calçados pela estética, o que neste caso pode propiciar o aparecimento ou agravamento do joanete.

Foram gerados requisitos do produto e do usuário estabelecidos pelas análises dos dados que objetivaram o desenvolvimento de um calçado ergonômico, atrativo e seguro para o público alvo. $\mathrm{Na}$ continuação desta pesquisa, pretende-se avaliar o modelo conceitual pela elaboração de protótipos e testes de usabilidade. Com o resultado desta avaliação, será possível refinar o modelo inicialmente proposto e, caso necessario, elaborar novos modelos de calçado em futuros desdobramentos. Por fim, fica evidente a necessidade de projetos centrados no ser humano, que trabalhem tanto com os fatores ergonômicos quanto estéticos que interferem no uso e aceitação do produto.

\section{BIBLIOGRAFIA}

GOMES Filho, João. Ergonomia do objeto: sistema técnico de leitura ergonômica. São Paulo:

Escrituras Editora, 2003.

GOONETILLEKE, Ravindra Stephen. The Science of Footwear. Florida: CRC Press, 2012.

MORAES, Anamaria de; MONT'ALVÃO, Cláudia. Ergonomia: Conceitos e aplicações. Rio de Janeiro: 2ab Editora, 2010.

NERY, Caio Augusto de Souza. Joanetes (Hálux Valgo). 2008. Disponível em:

$<$ http://www.unifesp.br/dortoped/pe/patologias/infor macao/joanetes-halux-valgo $>$. Acesso em: 20 ago. 2016.

SOUZA, Talita; HELD, Maria Silvia Barros de. A Estética como Conforto Psicológico na Moda. D: Vii Colóquio de Moda, 2011. 